teral and Enteral Nutrition: Executive Summary. Crit Care Med 2009;37(5):1757-1761.

2. McClave SA, Taylor BE, Martindale RG, Warren MM, Johnson DR, Braunschweig C, et al. Guidelines for the provision and assessment of nutrition support therapy in the adult critically ill patient: Society of Critical Care Medicine (SCCM) and American Society for Parenteral and Enteral Nutrition (A.S.P.E.N.). JPEN J Parenter Enteral Nutr 2016;40(2):159-211.

3. Reignier J, Mercier E, Le Gouge A, Boulain T, Desachy A, Bellec F, et al. Effect of not monitoring residual gastric volume on risk of ventilator-associated pneumonia in adults receiving mechanical ventilation and early enteral feeding: a randomized controlled trial. JAMA 2013;309(3):249-256.

4. Matsumoto T, Tomii K, Tachikawa R, Otsuka K, Nagata K, Otsuka K, et al. Role of sedation for agitated patients undergoing noninvasive ventilation: clinical practice in a tertiary referral hospital. BMC Pulm Med 2015;15:71.

5. Kogo M, Nagata K, Morimoto T, Ito J, Sato $\mathrm{Y}$, Teraoka $\mathrm{S}$, et al. Enteral nutrition is a risk factor for airway complications in subjects undergoing noninvasive ventilation for acute respiratory failure. Respir Care 2017;62(4): 459-467.

6. Liu Q, Gao Y, Chen R, Cheng Z. Noninvasive ventilation with helmet versus control strategy in patients with acute respiratory failure: a systematic review and meta-analysis of controlled studies. Crit Care 20(Can't get issue from record) 16; 20:265.

7. Patel BK, Wolfe KS, Pohlman AS, Hall JB, Kress JP. Effect of noninvasive ventilation delivered by helmet vs face mask on the rate of endotracheal intubation in patients with acute respiratory distress syndrome: a randomized clinical trial. JAMA 2016;315(22): 2435-2441.

\section{Noninvasive Respiratory Care Received by Individuals With Duchenne Muscular Dystrophy Since 1979}

\section{To the Editor:}

The authors of a recent review of Duchenne muscular dystrophy (DMD) management ${ }^{1}$ nicely pointed out that Dr Ishikawa's group reported survival for DMD subjects to a mean age of $39.6 \mathrm{y}$, but neither that 38 of them were dependent on continuous noninvasive ventilatory support nor that 8 had been extubated and 2 decannulated of tracheostomy tubes to continuous noninvasive ventilatory support despite having no ventilator-free breathing ability. None of the 17 who died did so from respiratory complications. There are currently $>80$ who are continuous noninvasive ventilatory support-dependent. Before eliminating tracheotomies in 1995, Dr Ishikawa's trached patients died at a mean age of $29 \mathrm{y}$. Today, there are $>20$ centers worldwide that manage DMD by continuous noninvasive ventilatory support and mechanical insufflation-exsufflation without ever resorting to tracheotomy for extubation failure, including the centers of the authors of this letter. ${ }^{2-5}$ In considering centers in multiple states, the authors of this review ${ }^{1}$ included no medical directors from them. The authors pointed out that Bach et $\mathrm{al}^{6}$ reported successful first-attempt extubation for $95 \%$ of 149 subjects with neuromuscular disease, but they overlooked that 20 had been continuous noninvasive ventilatory support-dependent with DMD. Indeed, the one who failed an initial extubation attempt subsequently succeeded, and none underwent tracheotomy.

The authors also overlooked the RESPIRATORY CARE follow-up paper ${ }^{7}$ on 96 more subjects successfully extubated to continuous noninvasive ventilatory support and mechanical insufflation-exsufflation as needed, including 12 more with DMD and no ventilator-free breathing ability. In 2013, a review of continuous noninvasive ventilatory support management by 6 of the $>20$ centers that provide it reported 40 consecutive successful extubations on "unweanable" subjects with DMD. ${ }^{8}$ Today, that figure is $>73$. Despite this, rather than "organize a support system of comprehensive instruction, equipping, and training in noninvasive management,"8 this review unfortunately continues to imply that tracheotomies must eventually become necessary for DMD, especially when conventional extubations fail. Indeed, they noted that 18 of 29 tracheostomies were performed due to acute respiratory illnesses and that $86 \%$ were performed before $21 \mathrm{y}$ of age, so clearly the continuous noninvasive ventilatory support extubation protocol was not used, and the 11 who underwent elective tracheotomy did not benefit from continuous noninvasive ventilatory support and mechanical insufflation-exsufflation either. Their review cited noninvasive ventilation, which has become synonymous with low spans of bi-level or continuous positive airway pressure, and mechanical insufflation-exsufflation without giving settings for ei- ther. We use full noninvasive ventilatory support settings, not low bi-level spans, and mechanical insufflation-exsufflation at $50-70 \mathrm{~cm} \mathrm{H}_{2} \mathrm{O}$ pressures, as was originally described to be effective. ${ }^{9}$

Their review concludes that "there have been few changes in pulmonary clinical practice" 1 and perpetuates unnecessarily invasive care, although no DMD patients would prefer it over noninvasive care.$^{10}$ It is also important to point out that with optimal noninvasive management, many if not most DMD patients become continuous noninvasive ventilatory support-dependent not only without being intubated or trached, but also without being hospitalized. ${ }^{8}$ Rather than evaluate and treat patients with DMD for sleep disordered breathing when, in reality, they have severe respiratory muscle dysfunction, should not a review of management include up to continuous noninvasive ventilatory support as well as vital mechanical insufflation-exsufflation, as cited in other consensuses? ${ }^{8}$

The following might also be pointed out: Although the review cited the need for cough flows and end-tidal $\mathrm{CO}_{2}$ monitoring, these are not routinely performed by pulmonary function testing, so it is unclear why the latter should be recommended; noninvasive ventilation has not only been available since the late 1980s, continuous noninvasive ventilatory support for DMD was described by Alexander and Johnson in 1979, ${ }^{11}$ by Bach et al in 1981,12 and subsequently others. Finally, this letter is fully sanctioned by 28 medical director authors of publications cited in a recent consensus on noninvasive management. ${ }^{8}$

John Bach MD

Department of Physical Medicine and Rehabilitation

Rutgers New Jersey Medical School Newark, New Jersey

Miguel Goncalves PhD

Department of Pulmonology University Hospital of S. Joao

Faculty of Medicine

University of Porto, Portugal

Michael Chiou MD

Department of Physical Medicine and Rehabilitation

Rutgers New Jersey Medical School Newark, New Jersey 
Nicholas Hart PhD

St Thomas' Hospital

London, United Kingdom

Michel Toussaint PhD

Ziekenhuis Inkendaal Rehabilitation

Hospital

Brussels, Belgium

The authors have disclosed no conflicts of interest.

DOI: $10.4187 /$ respcare. 05635

\section{REFERENCES}

1. Andrews JG, Soim A, Pandya S, Westfield CP, Ciafaloni E, Fox DJ, et al. Respiratory care received by individuals with Duchenne muscular dystrophy from 2000 to 2011. Respir Care 2016;61(10):1349-1359.

2. Ishikawa $Y$, Miura T, Ishikawa $Y$, Aoyagi T, Ogata H, Hamada S, Minami R. Duchenne muscular dystrophy: survival by cardio-respiratory interventions. Neuromusc Disord 2011;21(1):47-51.

3. McKim DA, Griller N, LeBlanc C, Woolnough A, King J. Twenty-four hour noninvasive ventilation in Duchenne muscular dystrophy: a safe alternative to tracheostomy. Can Respir J 2013;20(1):e5-e9.

4. Villanova M, Brancalion B, Mehta AD. Duchenne muscular dystrophy: life prolongation by noninvasive ventilatory support. Am J Phys Med Rehabil 2014;93(7):595-599.

5. Bach JR, Martinez D. Duchenne muscular dystrophy: prolongation of survival by noninvasive interventions. Respir Care 2011; 56(6):744-750.

6. Bach JR, Gonçalves MR, Hamdani I, Winck JC. Extubation of patients with neuromuscular weakness: a new management paradigm. Chest 2010;137(5):1033-1039.

7. Bach JR, Sinquee DM, Saporito LR, Botticello AL. Efficacy of mechanical insufflation-exsufflation in extubating unweanable subjects with restrictive pulmonary disorders. Respir Care 2015;60(4):477-483.

8. Bach JR, Gonçalves MR, Hon A, Ishikawa Y, De Vito EL, Prado F, Dominguez ME. Changing trends in the management of endstage respiratory muscle failure in neuromuscular disease: current recommendations of an international consensus. Am J Phys Med Rehabil 2013;92(3):267-277.

9. Bach JR. Update and perspectives on noninvasive respiratory muscle aids: part 2-the expiratory muscle aids. Chest 1994;105(5): 1538-1544.

10. Bach JR. A comparison of long-term ventilatory support alternatives from the perspective of the patient and care giver. Chest 1993;104(6):1702-1706.
11. Alexander MA, Johnson EW, Petty J, Stauch D. Mechanical ventilation of patients with late stage Duchenne muscular dystrophy: management in the home. Arch Phys Med Rehabil 1979;60(7):289-292.

12. Bach J, Alba A, Pilkington LA, Lee M. Long-term rehabilitation in advanced stage of childhood onset, rapidly progressive muscular dystrophy. Arch Phys Med Rehabil 1981;62(7):328-231.

\section{Noninvasive Respiratory Care \\ Received by Individuals With Duchenne Muscular Dystrophy Since 1979—Reply}

\section{In reply:}

We commend Dr Bach and his colleagues for advancing and optimizing noninvasive respiratory care for individuals with neuromuscular disease since the late 1970s. However, we believe he may have misinterpreted the aim and purpose of our study results, ${ }^{1}$ and we would like to clarify. In recent years, emphasis on the use of noninvasive respiratory aids has only increased, and this emphasis has been endorsed in numerous consensus statements on Duchenne muscular dystrophy (DMD) respiratory care. Despite the emphasis on noninvasive respiratory management in the published guidelines, we found significant variability in monitoring for respiratory muscle weakness and in the use of noninvasive respiratory care devices among the neuromuscular centers in our study. ${ }^{1}$ Furthermore, there is a paucity of literature on adherence to these published guidelines and very little information on reasons why providers may deviate from the recommended care. Our data suggest that the guidelines for respiratory care have not been universally embraced, at least in the centers that we examined. This "care gap" might be due to potentially correctable barriers (eg, the need for further clinician education, a shortage of therapists trained in noninvasive aids, or the need for improved insurance coverage for the necessary equipment). Alternatively, the gap might represent a decision by providers to deviate from the recommendations (eg, due to local expertise and preference for ventilation via tracheostomy)

Our study reported descriptive data on information collected retrospectively for a surveillance network from medical records. Our sole intention was to compare data available with the care management guidelines published and determine whether any trends or changes could be identified. The aim of our paper was to report on DMD respiratory care management from medical record data available through 2011 for individuals cared for in select areas that are affiliated with MD STARnet and to compare those data with the published care management guidelines. We very specifically did not set any standards of care, attempt to criticize local practice, nor imply any perspectives on the use of tracheostomies in DMD, since this was not the purpose of our work. One idea that our article does suggest is that standards of care need to be widely enacted-and if they cannot be achieved locally they may not achieve their intent, which is to benefit large groups of patients.

We appreciate the opportunity to respond to the letter of Dr Bach et al regarding our manuscript. We hope that their letter and our response will spark a discussion on how to address barriers to guideline implementation. The best way to ventilate patients with DMD is a complex issue that must respect the voice and choice of patients. For additional perspectives from individuals with DMD using noninvasive and invasive ventilation, we encourage readers to review Ventilation and Duchenne ${ }^{2}$ from DMD Pathfinders (http://www.dmdpath finders.org, Accessed May 17, 2017), a user-led organization whose mission is to "promote choice and control, and quality of life for teenagers and adults with DMD."

Jennifer G Andrews PhD Department of Pediatrics University of Arizona College of Medicine Tucson, Arizona

Aida Soim PhD

New York State Department of Health Albany, New York

Shree Pandya PT DPT MSc

Department of Neurology University of Rochester Rochester, New York

Christina P Westfield RN

New York State Department of Health Albany, New York

Emma Ciafaloni MD

Department of Neurology

University of Rochester

Rochester, New York 